\title{
Biossíntese de Produtos Naturais
}

\author{
Ana M. Lobo e Ana M. Lourenço (eds) \\ IST Press, Colecção “Ensino da Ciência e da Tecnologia”, Lisboa, 2007, \\ n. ${ }^{\circ}$ de páginas: 276, preço(PVP): € 21,00, ISBN 978-972-8469-50-4
}

M. M A T I L E M A R Q U E *

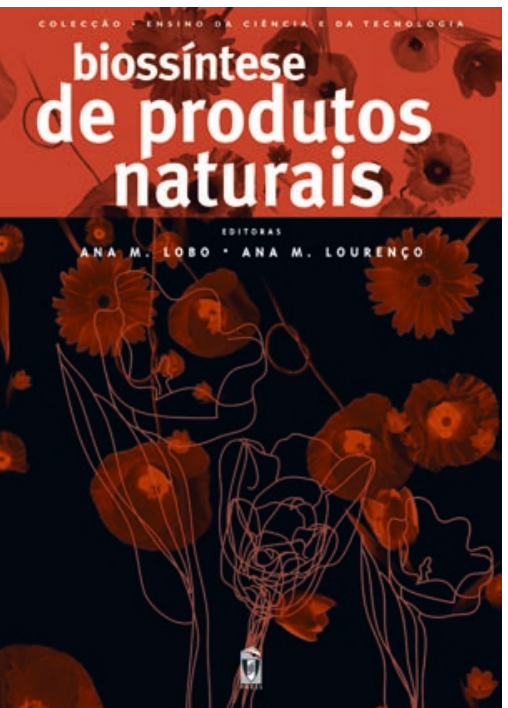

O presente livro reflecte, de muito perto, o programa de um curso semestral típico em Biossíntese de Produtos Naturais, ministrado a alunos do $2 .^{\circ}$ ciclo universitário de Química ou áreas afins. Muito embora conte com a contribuição de vários autores, é notória uma grande coerência científica e de estilo que pressupõe um profundo trabalho de edição por parte das professoras Ana Lobo e Ana Lourenço.

A obra inicia-se, muito apropriadamente, com um capítulo sobre as metodologias usuais de elucidação de vias biossintéticas, que engloba um útil resumo sistemático dos mecanismos das reacções mais usuais em biossíntese, evidenciando as suas semelhanças com os mecanismos das reacções orgânicas, com que os leitores estão em geral mais familiarizados. A abordagem

\footnotetext{
* Departamento de Engenharia Química e Biológica, Instituto Superior Técnico (matilde.marques@ist.utl.pt)
}

\begin{abstract}
A biossíntese dos produtos naturais é, de entre as áreas modernas da química, uma das mais recentes e representa nos conceitos e na metodologia a intersecção da química com a biologia molecular. Com efeito o conhecimento dos mecanismos biossintéticos, investigados a partir do momento em que os radioisótopos ficaram disponíveis no fim da Segunda Grande Guerra, está hoje no cerne de inúmeras actividades do químico, quer se trate de intervenções nas indústrias farmacêutica, fermentativa, ou alimentar, quer se trate de problemas das áreas da toxicologia, agricultura ou remediação ambiental.
\end{abstract}

(do prefácio)

é moderna, sendo um sinal dos tempos a preocupação, que se saúda, em introduzir o termo metaboloma como conjunto de metabolitos endógenos de uma dada espécie, que constituem a sua "assinatura" molecular e cuja manipulação poderá, a médio prazo, conduzir a inúmeras aplicações.

Seguem-se vários capítulos dedicados às principais vias biossintéticas conducentes a metabolitos secundários, onde se reforça a preocupação com a compreensão dos mecanismos reaccionais envolvidos. Esta é uma opção acertada, já que permite ao leitor uma racionalização da grande diversidade de estruturas que é possível encontrar, bem como a aquisição da capacidade de propôr percursos biossintéticos plausíveis (susceptíveis de virem a ser testados e de sobre eles se intervir) para novos metabolitos.

Regista-se ainda com muito agrado a introdução de dois capítulos não convencionais em obras deste tipo. Um destes capítulos é dedicado à comunicação química na natureza, sendo salientadas as possibilidades e benefícios da utilização racional de semioquímicos, por exemplo no controlo de pragas. O outro capítulo discute a utilização de substâncias proíbidas no desporto, um tema de grande actualidade e que raramente se vê tratado de modo sistemático.

O livro está, ainda, enriquecido com um conjunto interessante de problemas. A leitura é muito agradável e o grafismo é excelente. Sendo o público-alvo constituído prioritariamente por estudantes do 2. ${ }^{\circ}$ ciclo na área da Química, é previsível que venha também a ser utilizado por estudantes de doutoramento com lacunas de formação em biossíntese e mesmo por investigadores mais seniors que necessitem de recordar conceitos. O aparecimento, em língua portuguesa, de obras desta envergadura é uma iniciativa que se aplaude e que se espera venha a ter continuidade. 


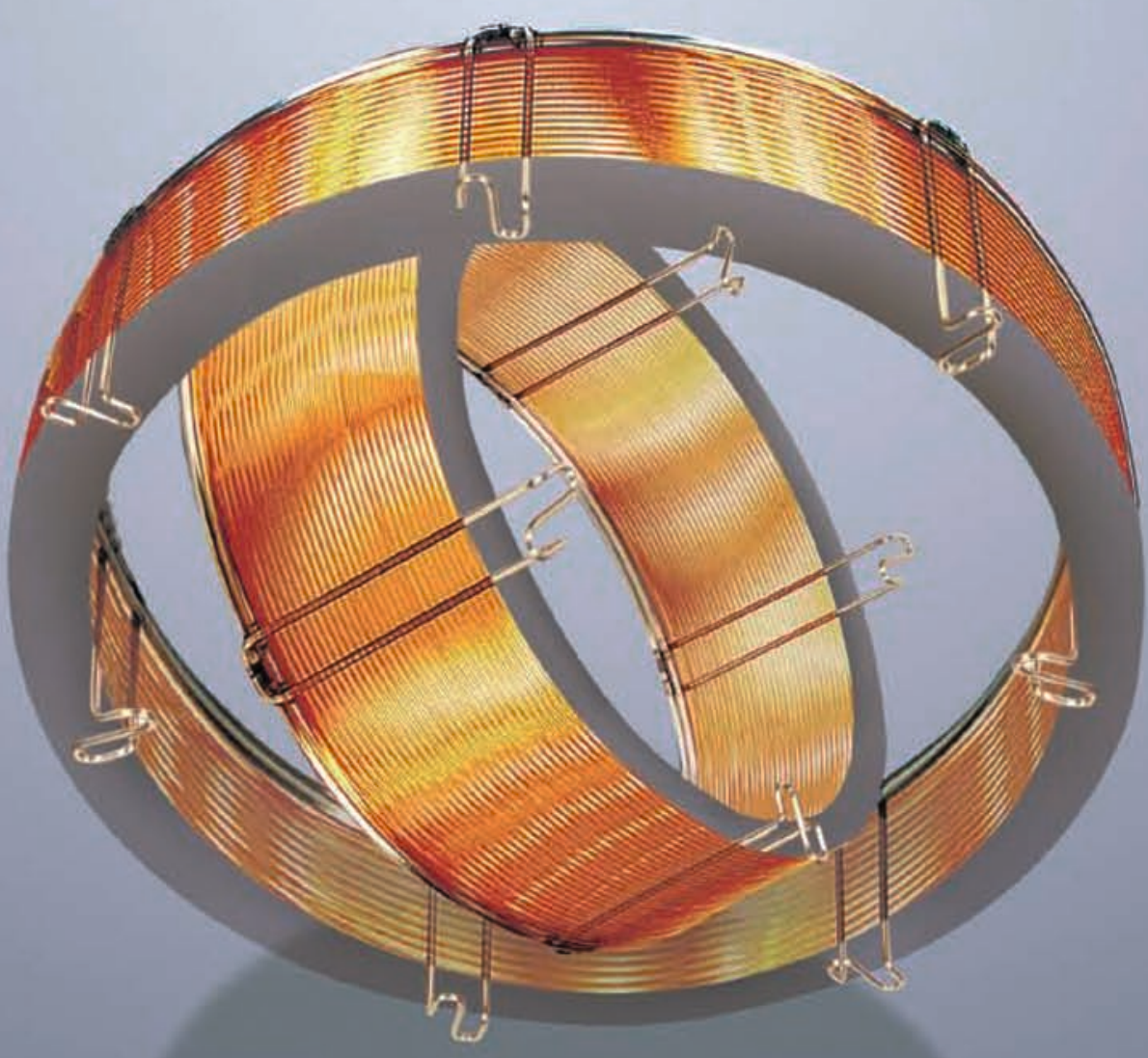

\section{Innovation Comes In Many forms}

Zebron - Revolutionizing the Field of Gas Chromatography

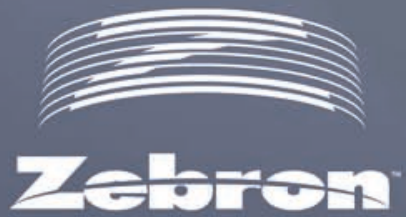

\begin{tabular}{ll}
\hline Zebron"' ZB-WAXPLus: & Ideal for polar compounds. 100\% aqueous stable. \\
\hline Zebron MultiResidue": & $\begin{array}{l}\text { Perfect for pesticide analysis. For US EPA 8081A, } \\
\text { baseline resolution is achieved in just } 10 \text { minutes! }\end{array}$ \\
\hline $\begin{array}{l}\text { Zebron ZB-1HT Inferno" } \\
\text { and ZB-5HT Inferno: }\end{array}$ & $\begin{array}{l}\text { The world's highest temperature non-metal GC } \\
\text { columns. Provides true boiling point separation } \\
\text { for hydrocarbon distillation methods. }\end{array}$ \\
\hline
\end{tabular}

Zebron has been revolutionizing the field of gas chromatography with its commitment to producing innovative, high quality columns that meet the needs of today's gas chromatographers. Our scientists have developed key technologies, such as Engineered Self Cross-linking (ESC) and Arylene Matrix Technology (AMT), to create GC columns that provide high temperature stability, improved lifetime, low bleed, and low activity. Each and every column is individually QC tested to ensure that they have excellent batch-to-batch reproducibility so you will have reliable and reproducible results, every time. For a column that best meet your needs, please contact your local Phenomenex Technical Specialist.

Zetron, 2B-14T interno, 28-5HT Interno, Engineered Selt Cross-Inking, Arylene Matrix Technology, and MultiResidue are

menex, inc. All rights reserved.

[๑]

ww.phenomenex.com

Thenomenex products are avaliable werldwide. For the distributor in your country, contact

\begin{tabular}{|c|c|c|c|c|c|c|c|c|c|c|c|c|}
\hline $\begin{array}{c}\text { tel: } \\
\text { email: }\end{array}$ & $\begin{array}{l}\text { Australia } \\
02-9428-6444 \\
\text { into@ } \\
\text { phenomenex.com.au }\end{array}$ & $\begin{array}{l}\text { Austria } \\
01-319-1301 \\
\text { anfragee } \\
\text { phenomenex.com }\end{array}$ & $\begin{array}{l}\text { Canada } \\
\text { (800) } 543-3681 \\
\text { into@ } \\
\text { phenomenex.com }\end{array}$ & $\begin{array}{l}\text { Denmark } \\
48248048 \\
\text { dkinfo@ } \\
\text { phenomenex.com }\end{array}$ & $\begin{array}{l}\text { France } \\
0130092110 \\
\text { franceinfo@ } \\
\text { phenomenex.com }\end{array}$ & $\begin{array}{l}\text { Germany } \\
06021-58830-0 \\
\text { anfrage@ } \\
\text { phenomenex.com }\end{array}$ & $\begin{array}{l}\text { Italy } \\
051736176 \\
\text { italiainfo@ } \\
\text { phenomenex.com }\end{array}$ & $\begin{array}{l}\text { Ireland } \\
012475405 \\
\text { eireinfo@ } \\
\text { phenomenex.com }\end{array}$ & $\begin{array}{l}\text { New Zealand } \\
09-4780951 \\
\text { info@ } \\
\text { phenomenex.co.nz }\end{array}$ & $\begin{array}{l}\text { Puerto Rico } \\
(800) 541-H P L C \\
\text { info@ } \\
\text { phenomenex.com }\end{array}$ & $\begin{array}{l}\text { United Kingdom } \\
\text { 01625-501367 } \\
\text { ukinfo@ } \\
\text { phenomenex.com }\end{array}$ & $\begin{array}{l}\text { USA } \\
\text { (310) 212-0555 } \\
\text { info@ } \\
\text { phenomenex.com }\end{array}$ \\
\hline
\end{tabular}

